\title{
CHARACTERIZING TRANSPORT PROPERTIES IN KARST CONDUITS UNDER DIFFERENT HYDROLOGIC CONDITIONS
}

\author{
Elienisse Rodríguez-Medina \\ University of Puerto Rico \\ Mayagüez,Puerto Rico,00681,elienisse.rodriguez@upr.edu \\ Ingrid Y. Padilla \\ University of Puerto Rico \\ Mayagüez, Puerto Rico,00681, ingrid.padilla@upr.edu
}

Fernando Pantoja

University of Puerto Rico

Mayagüez, Puerto Rico,00681,fernando.pantoja@upr.edu

\section{Kateleen Vargas}

University of Puerto Rico

Mayagüez,Puerto Rico,00681, kateleen.vargas@upr.edu

\section{Norma I. Torres}

University of Puerto Rico

Mayagüez,Puerto Rico,00681,norma.torres@upr.edu

\begin{abstract}
Karst terrains contain very productive aquifers. The hydraulic and hydrogeological characteristics of karst aquifers make these systems capable of storing and transporting large amounts of water, but also highly vulnerable to contamination. Their extremely heterogeneous nature prevents accurate prediction of contaminant fate and transport. Even more challenging is to understand the impact of hydrologic condition changes on fate and transport processes. This study aims at characterizing changes in transport processes in the karst groundwater system of northern Puerto Rico under different hydrologic conditions. The study involves injecting rhodamine $\mathrm{wt}$ and uranine tracers into a spring cave, and monitoring concentrations at different points along the cave during different rainfall conditions. Results show that transport processes of solutes in eogenetic karst with temporal rainfall patterns affect the hydrogeologic flow regime. Preliminary results suggest significant differences in fate and transport characteristics under different hydrologic conditions.
\end{abstract}

\section{Introduction}

Karst landscapes are developed by karstification. This process results in the dissolution of carbonate rocks, such as limestones, in the presence of carbon dioxide and water, which leads to development of fractured carbonated rocks into open fractures, conduits, and caves (Hartmann et al., 2014; Kresic, 2013). The porosity and transmissive zones thorough these formations result in strong heterogeneity, permitting variable pathways for groundwater flow (Hartmann et al., 2014; Kresic, 2013). The hydraulic and hydrogeological characteristics make these aquifers capable of storing and transporting large amounts of water. In the world, karst regions cover approximately $20 \%$ of the planet and supply around $25 \%$ of the population's drinking water (Morales, 2010; Ford and Williams, 2007). However, contamination can enter the groundwater system through recharge areas, which can be the connections between surface and subsurface features associated with sinkholes, sinking streams, caves, conduits, and springs. Water in karst systems moves through fractures, conduits, and the rock matrix. Differences in flow capacity through these regions give rise to a spectrum of flow modes, which range from slow, laminar flows to high velocity, highly turbulent flows. There is still a lack of understanding of the complicated nature of groundwater flow through karst aquifers.

Tracing techniques are powerful tools to understand water movements and contaminant transport in karst sys- 
tems. Cave tracer test can provide more detailed information about flow velocities and transport parameters. Injection in sinkholes or streams can deliver information on regional flow paths, from injection and recovery (Lauber, Ufrecht, \& Goldscheider, 2014). Caves accessibility is relatively small, but its water path exploration can provide more details of internal structure and hydraulic functioning of the aquifer (Goldscheider, Meiman, Pronk, \& Smart, 2008).

Previous publications show investigation of karst aquifers in caves using uranine florescent dye. Results indicated uranine breakthrough curves (BTCs) recovers almost $100 \%$ for low and high flows. But, in low flow recovery was between $27 \%$ and $75 \%$ (Göppert \& Goldscheider, 2008). Many transport studies have been conducted in telogenetic karst systems (I. Y. Padilla \& Vesper, 2018). This works focuses on open-channel cave conduit characteristics in an eogenetic karst system in northern Puerto Rico. The work relies on tracer tests to assess hydraulic parameters of these systems and the influenced of this component under different rainfall events, wet and dry seasons.

\section{Study Area (Site)}

The island of Puerto Rico is located between the Caribbean Sea and the North Atlantic Ocean. Historically, Puerto Rico is subjected to two seasonal periods based on monthly rainfall: a wet season from May through November and a dry season from December through April (Cherry, 2001; Torres et al., 2018; Yu et al., 2015).

In Puerto Rico, karst regions cover $27.5 \%$ of the island, from which $19 \%$ is located on the northern region, and contains the most productive aquifer of the island (Molina-Rivera, 2009). The landscape in this region is characterized by deep dolines, separated by high hills called mogotes (Lugo et al. 2001). The northern karst region contains an upper and lower karst aquifer, separated by a confined layer of clay, mudstone and marl. The upper aquifer is within two hundred meters of the island surface and it is considered unconfined. It is comprised of the Aymamón and Aguada Limestones. The Aymamón unit overlies the Aguada limestone. Both are formed of predominant backreef limestone deposits, which in the Aymamón formation are predominantly chalk when compared to the more crystalline in the Aguada forma- tion (Veve, and Taggart, 1996). The Aymamón is overlain by Quaternary deposits of sandy and silty clays. The lower aquifer is at greater depths, and it is considered confined. It is mostly comprised of the Montebello and Lares Limestone formations (Renken et al. 2002).

These aquifer system in the northern karst region of Puerto Rico serves as a main source of fresh water for thousands of residents and industries. (Veve and Taggart, 1996, Padilla et al., 2011). The aquifers have sustained population and industrial growth in the area. This growth has unfortunately resulted in a long history of contamination from accidental spills, deliberate disposal, landfills and clandestine waste disposal (Yu et al., 2015; Padilla, Irizarry, \& Steele, 2011). Major contamination in the region has led to twelve superfund sites, located in the northern area, out of the twenty-five found in the whole island (Figure 1; EPA, 2019).

The tracer study was performed in El Tallonal natural reserve, located in the municipality of Arecibo, Puerto Rico (Figure 1). The Tallonal site lies on the upper aquifer of the northern karst region. The Tallonal spring flows from within a cave and is considered a conduitdominated spring (Quinones-Aponte, 1986). Based on its cartography (Figure 2), the cave is 110 meters long and has heights of up to about $4 \mathrm{~m}$ with spring water temperatures of approximately $23^{\circ} \mathrm{C}$.

\section{Methodology}

The effect of hydrologic conditions on transport characteristics in the cave conduit at Tallonal was assessed by conducting tracer test at different hydrologic conditions, such as rainfall. The specific methods of analysis are described below.

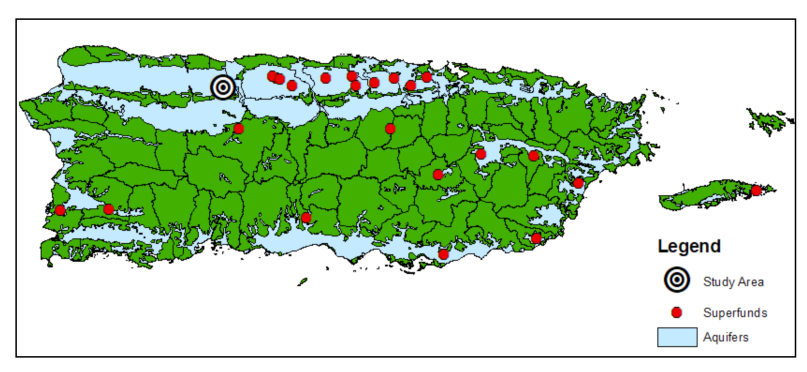

Figure 1. Principal aquifers and superfunds in Puerto Rico (modified from Renken et al., 2002) 


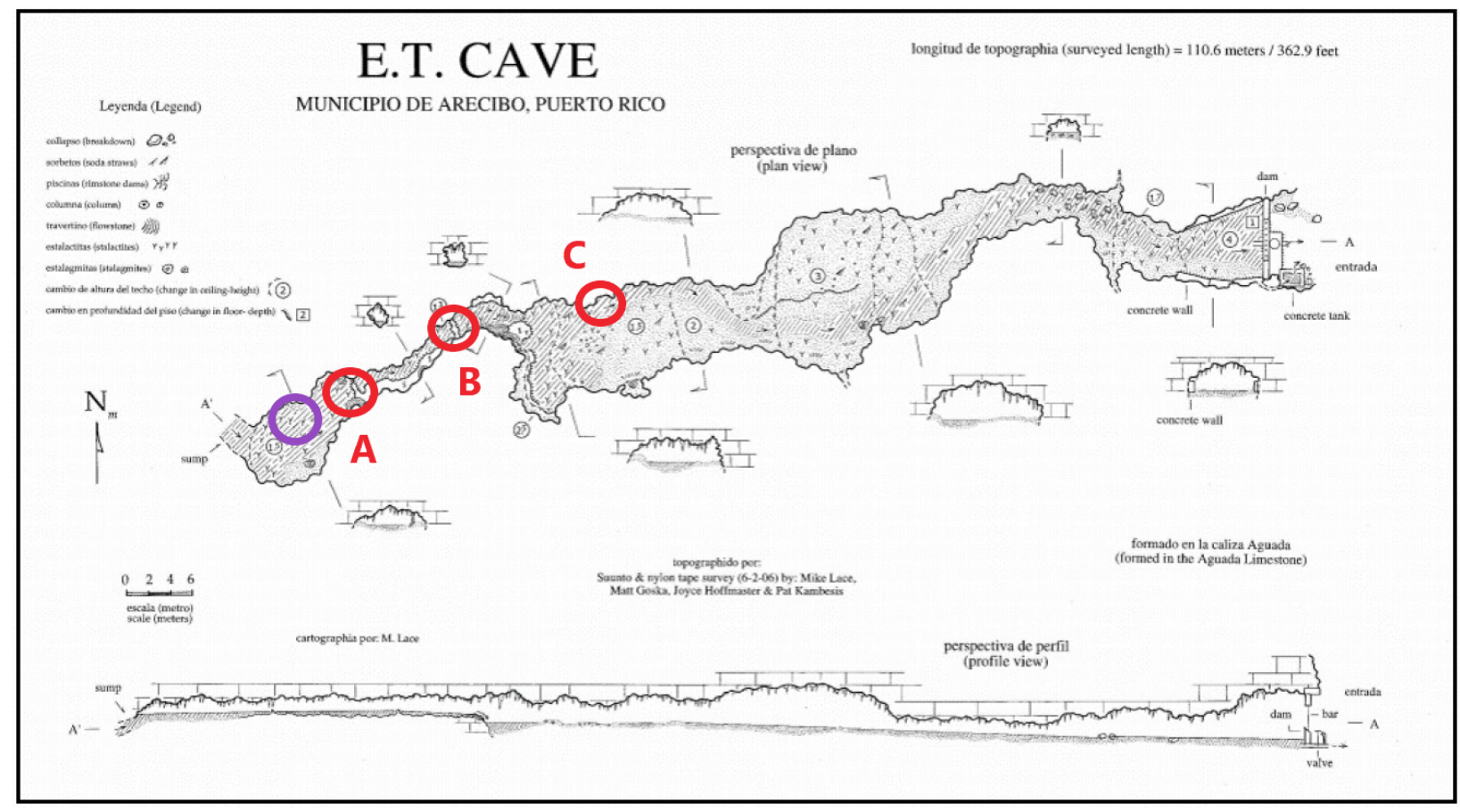

Figure 2. Tallonal Spring Cartography (M. Lace). Purple and red circles show tracer injection and sampling point sites, respectively.

\section{Different Hydrological Conditions}

The seasonal hydrological conditions were evaluated and classified as "extremely dry", "dry", "wet", and "extremely wet", according to the approximate total monthly precipitation. Precipitation data were obtained from National Oceanic and Atmospheric Administration (NOAA) stations in the Arecibo area. Two NOAA Stations (NOAA, 2019) with daily precipitation data from 2013 to 2019 were used to calculate total monthly precipitation. Quartiles $\left(\mathrm{Q}_{\mathrm{i}}\right)$ were calculated using the total monthly precipitation from the stations over the 7-year period: if the total monthly precipitation (TMP) for the month of measurement was less than Q1, that month was classified as "extremely dry"; if TMP was greater than $\mathrm{Q}_{1}$ but less than $\mathrm{Q}_{2}$, that month was classified as "dry"; if TMP was greater than $\mathrm{Q}_{2}$ but less than $\mathrm{Q}_{3}$, it was classified as "wet"; and if TMP was greater than $\mathrm{Q}_{3}$, it was classified as "extremely wet". Total antecedent rainfall (TAR) is defined as the total amount of rain falling within months prior to the tracer test month. TAR is believed to influence the amount of groundwater stored in the systems and potentially discharging into the cave conduit (Longenecker et al., 2017).

\section{Tracers}

To meet the objective of this study, several tracer tests were conducted inside the Tallonal cave using uranine and rhorodamine wt fluorescent dyes. These tracers were selected because they are commonly used for groundwater tracing studies (Axelsson, Björnsson, \& Montalvo, 2005; Hartmann et al., 2014), are inexpensive, and nontoxic and have low detection limits (Axelsson et al., 2005). The detection limits for uranine and rodamine wt are $10^{-3} \mu \mathrm{g} / \mathrm{L}$ and $10^{-2} \mu \mathrm{g} / \mathrm{L}$, respectively.

Five tracer tests were performed. In 2018, two experiments were conducted in July and October, while in 2019, experiments were conducted in February, March and June. A total mass of $2.88 \mathrm{~g}$ was injected for both uranine and rhodamine wt during the July and October 2018 test, whereas a total mas of $1.44 \mathrm{~g}$ was injected for the other experiments.

\section{Data Collection}

Water samples were collected before the tracer injection as background concentrations in the spring. After the in- 
jection, samples were collected using a discrete quantitative sampling method (Goldscheider et al., 2008). Discrete sampling consists in taking manual samples in plastics bottles at different points and times. All the experiments lasted one hour, except the one made in July, which lasted half-hour. Samples were collected every 20 seconds for the first five minutes. Thereafter, samples were collected at $8,11,14,17,20,23,26,30,35,40,45$, 50,55 and 60 minutes. Dye concentrations were measured after collection by analyzing water samples with a field spectrophotometer.

In each experiment, the manual samples were collected in three different points inside the cave, shown as point A, point $B$ and Point $C$ in Figure 2. Point A was 6.2 meters from the injection point, point $\mathrm{B}$ was 12.3 meters from point $\mathrm{A}$ and Point $\mathrm{C}$ was 22.7 meters from point A. Flow $\left(\mathrm{Q}_{\mathrm{m}}\right)$ was measured at point $\mathrm{B}$ using a portable velocity meter (Hach FH950) and sectional area during the 2019 tracer experiments.

\section{Data Analysis}

Temporal concentration distributions (TCDs) at each sampling location was analyzed qualitatively and quantitatively using the methods of moment. Equation 1 was used to obtain temporal moments (Goldscheider et al., 2008) (Chapra, 2003).

$$
M_{n}=\int_{-\infty}^{\infty} C(x, t) t^{n} d t
$$

\section{Equation 1}

Where $M_{n}$ represents the moment of order $n=0,1,2$.

Time of travel ( $t_{t}$; Equation 2) was estimated as the first moment $\left(\mathrm{M}_{1}\right)$ divided by the zeroth moment $\left(\mathrm{M}_{0}\right)$.

$$
t_{t}=\frac{M_{1}}{M_{0}}=\frac{\int_{-\infty}^{\infty} C(x, t) t^{1} d t}{\int_{-\infty}^{\infty} C(x, t) d t}
$$

\section{Equation 2}

Velocity is estimated as the distance between two points divided by the time of travel between those points. Estimated flows $\left(Q_{e}\right)$ were calculated from velocity estimates and measured cross sectional areas at point of measurements. The variance $\left(\sigma^{2}\right)$ of the temporal concentration distribution (Equation 3), which is related to dispersive and mass transfer processes, was calculated as

$$
\sigma^{2}=\frac{M_{2}}{M_{0}}-t_{t}=\frac{\int_{-\infty}^{\infty} C(x, t) t^{2} d t}{\int_{-\infty}^{\infty} C(x, t) d t}-t_{t}
$$

\section{Equation 3}

Total mass recovered was estimated as the product of $\mathrm{M}_{0}$ and flow. When available, measured flow was used to estimate recovered mass. Otherwise, flows estimated from velocity estimates (velocity $\mathrm{x}$ flow area) using travel times were used. Percent mass recovered was estimated as the fraction of total mass recovered over the injected mass.

\section{Results}

\section{Categorical Rainfall}

The quartiles obtained from the monthly total precipitation analysis of the two Arecibo station closer to the Tallonal Spring are 82.3, 128.8 and 192 for $Q_{1}, Q_{2}$, and $\mathrm{Q}_{3}$, respectably. Results show that February and March of 2019 are, as expected, extremely dry and dry and October 2018 and June 2019 are wet (Table 1). In contrast, July 2018 is extremely dry, which is not as expected based on historical records.

\section{Results of Tracer Injections}

All tracer experiments show TCDs with single peaks. Though rhodamine wt and uranine tracers tend to show similar behavior (Figure 3) in almost all experimental sites along the cave, uranine concentrations and their respective recoveries are lower. Overall, recovery of uranine is about $43 \%( \pm 13 \%)$ of that for rhodamine

\begin{tabular}{|l|c|l|}
\hline $\begin{array}{l}\text { Experiment } \\
\text { Date }\end{array}$ & $\begin{array}{l}\text { Precipitation } \\
(\mathrm{mm})\end{array}$ & $\begin{array}{l}\text { Categorical } \\
\text { Hydrologic } \\
\text { Regime }\end{array}$ \\
\hline July 2018 & 67.2 & Extremely Dry \\
October 2018 & 161.4 & Wet \\
February 2019 & 58.1 & Extremely Dry \\
March 2019 & 122.2 & Dry \\
June 2019 & 157.6 & Wet \\
\hline
\end{tabular}

Table 1. Statistic results for total monthly rainfall in two NOAA Arecibo Stations. 
wt. We therefore, focus this work on the rhodamine wt results. As expected, TCDs show earlier arrival times, higher relative concentrations, and lower variance at the measurement points closer to injection (Figure 4; Table 2).

Results show that TCDs vary depending on the hydrologic regime (Table 1), but also on other factors such as the total antecedent rainfall. For instance, a TCD for February 2019, which is categorized as extremely dry, shows that maximum concentrations arrive a given distance at later times than October 2018, which is catego-

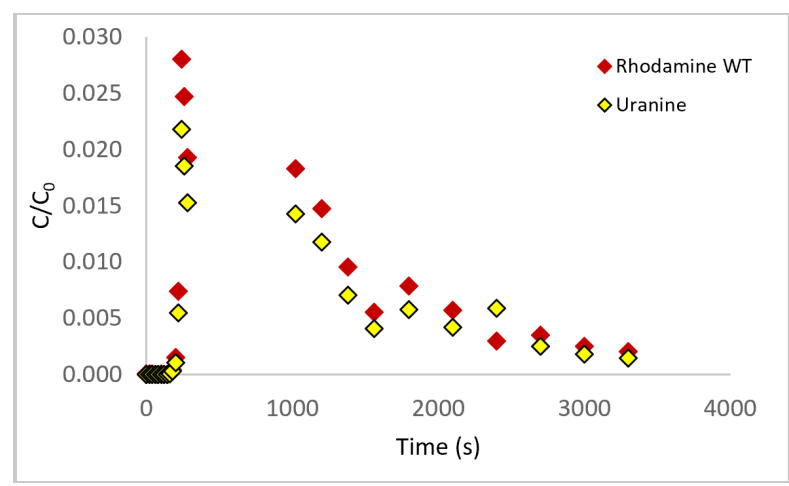

Figure 3. Temporal relative concentration distributions for rhodamine wt and uranine at point B on October 2018.

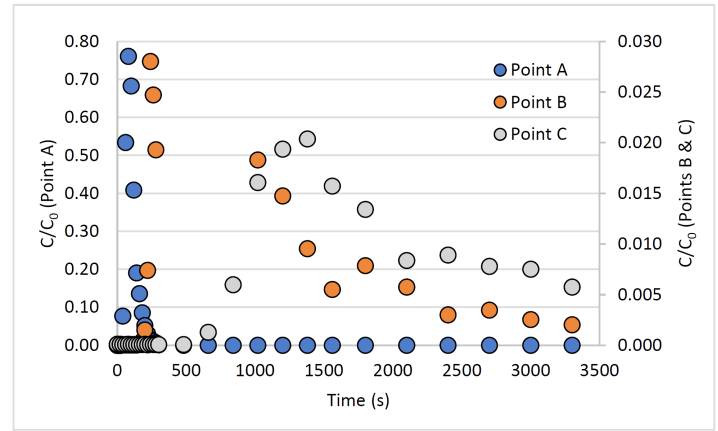

Figure 4. Temporal relative concentration distributions for rhodamine wt at points $A, B$, and $\mathrm{C}$ on October 2018.

\begin{tabular}{|c|c|c|c|}
\hline & $A$ & $B$ & $C$ \\
\hline $\begin{array}{c}\text { Time of travel } \\
(s)\end{array}$ & 109.5 & 1550.3 & 1814.2 \\
\hline $\begin{array}{c}\text { Variance } \\
\left(s^{2} \times 10^{9}\right)\end{array}$ & 1.64 & 2.35 & 2.49 \\
\hline
\end{tabular}

Table 2. Time of travel and variance of TCDS for rhodamine wt tracer at points $A, B$, and $C$ on October 2018. rized as wet (Figure 5). However, peak concentrations for July 2018, which is also categorized as extremely dry, tend to arrive at earlier times than those for October 2018 (Figure 5). This is attributed to high total antecedent rainfall (Table 3) before July 2018, relative to that in October 2018 and February 2019. A sensitivity analysis relating time of travel to TAR indicates that the 3 months preceding the month of testing show the strongest relationship. Results indicate that solute transport in the cave, which lies within an eogenetic karst, is influenced by conduit flow entering the system during rain events and flow previously stored in the groundwater systems during previous rainfall events. Estimated velocities within the cave tend to increase with antecedent rainfall and vary along reaches (Table 3). Because of the wide ranges in TCD tailing, as reflected in the
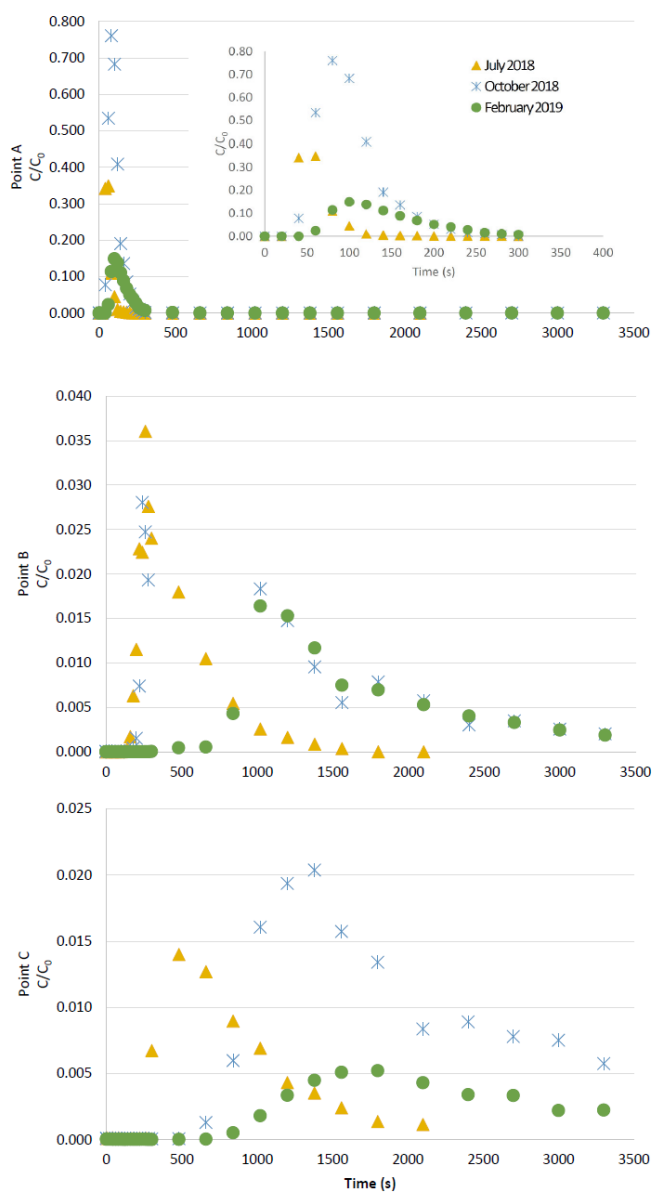

Figure 5. Temporal relative concentration distributions for rhodamine wt at points $A$, $B$, and $C$ at various dates and hydrologic regimes. 


\begin{tabular}{|l|c|c|c|c|c|}
\hline Date & $\begin{array}{l}\text { Antecedent } \\
\text { Rainfall } \\
(\mathrm{mm})\end{array}$ & Point & $\begin{array}{l}v_{M 1} \\
(\mathrm{~m} / \mathrm{s})\end{array}$ & $\begin{array}{l}v_{\max } \\
(\mathrm{m} / \mathrm{s})\end{array}$ & $\begin{array}{l}\sigma^{2} \\
\left(\mathrm{~s}^{2}\right) \\
x 10^{5}\end{array}$ \\
\hline July & 499 & $\mathrm{~A}$ & 0.10 & 0.10 & 4.45 \\
2018 & & $\mathrm{~B}$ & 0.03 & 0.06 & 424 \\
& & $\mathrm{C}$ & 0.05 & 0.05 & 1020 \\
\hline October & 365 & $\mathrm{~A}$ & 0.06 & 0.08 & 16400 \\
2018 & & $\mathrm{~B}$ & 0.01 & 0.08 & 23000 \\
& & $\mathrm{C}$ & 0.04 & 0.01 & 21500 \\
\hline February & 273 & $\mathrm{~A}$ & 0.04 & 0.06 & 0.125 \\
2019 & & $\mathrm{~B}$ & 0.01 & 0.01 & 0.738 \\
& & $\mathrm{C}$ & 0.06 & 0.02 & 0.690 \\
\hline March & 188 & $\mathrm{~A}$ & 0.06 & 0.10 & 0.215 \\
2019 & & $\mathrm{~B}$ & 0.01 & 0.01 & 6.05 \\
& & $\mathrm{C}$ & 0.01 & 0.01 & 3.82 \\
\hline June & 331 & $\mathrm{~A}$ & 0.05 & 0.10 & 0.211 \\
2019 & & $\mathrm{~B}$ & 0.01 & 0.02 & 6.38 \\
& & $\mathrm{C}$ & 0.01 & 0.01 & 3.34 \\
\hline
\end{tabular}

Table 3. Antecedent rainfall, estimated velocities, and variances at points $A, B$, and $C$ at different test dates.

variances (Table 3), velocities estimated from M1 travel times $\left(\mathrm{v}_{\mathrm{M} 1}\right)$ differ at times from velocities estimated from the arrival of the peak concentration $\left(\mathrm{v}_{\max }\right)$. Peak concentrations are logarithmically related to $\mathrm{v}_{\max }$ (Figure 6), suggesting advection-controlled maximum concentrations. TCD variances are generally higher for the farthest downstream measuring point (point $\mathrm{C}$ ) and tend to increase with antecedent rainfall and rainfall-at-month of testing. The highest variances are associated with tracer test conducted in July and October of 2018, and show the highest total antecedent rainfall. The lowest variance is associated with the test conducted in February 2019, which does not have the lowest TAR, but does have the lowest rainfall at the month of testing. A non-parametric index representing the sum of ranks for rainfall-at-month of testing and TAR indeed relates directly to the average of variances and the ranking of variances. These results suggest that both rainfall patterns during the month of testing and total antecedent rainfall affect the variance by both affecting velocity variations along the cave, mechanical dispersion and dilution processes.

\section{Flow Estimates}

During the tracer experiments performed in February, March, and June of 2019 flow measurements at point B were compared with flows estimated as the product of cross-sectional area and velocities derived from tracer test. Although only 3 points were compared, result show a linear fit (Figure 7). Measured and tracer-estimated flows are similar at the lower flow ranges. At the higher flow, the tracer-estimated flow is lower than the measured one. This is attributed to slower tracer velocities estimated from the moment analysis as a result of later time of arrival of the tracer's center of mass and greater tailing of the breakthrough curve (Point B, Figure 5). The slower velocity from the tracer test compared to the measured ones suggests additional sources of water entering downstream of the injection point during those conditions.

Because flows estimated from tracer tests were more complete, they were used for the analysis. Results show that the highest flow was obtained during the July 2018

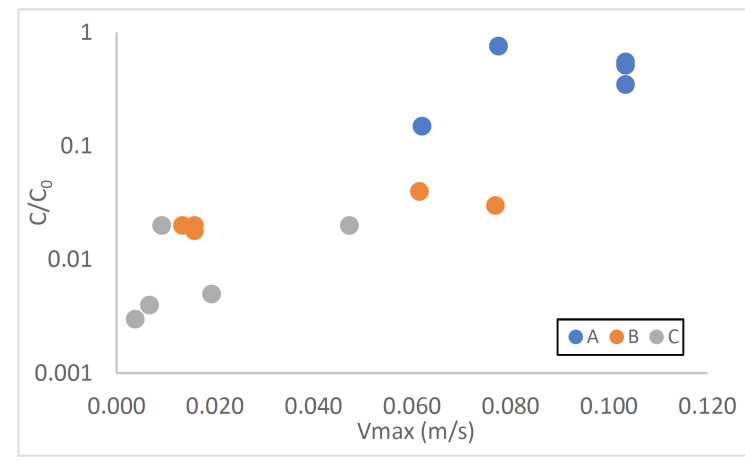

Figure 6. Velocity at peak concentration vs relative peak concentrations.

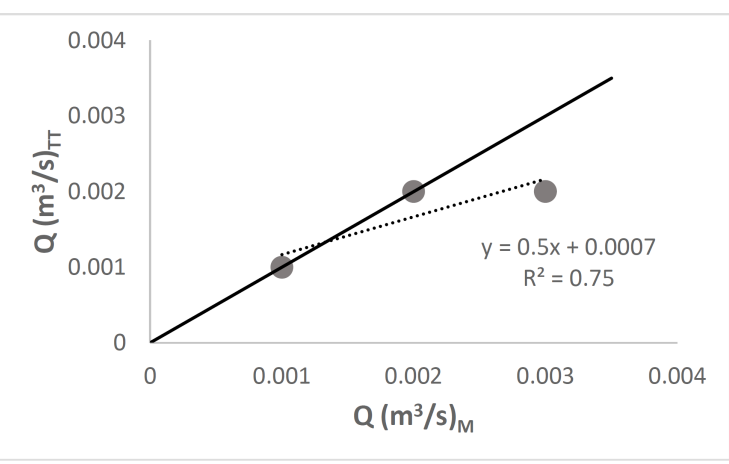

Figure 7. Comparison of measured flows (QM) with those estimated form tracer tests (QTT). The circles represent the data, the dash line the linear regression of the data, and the black line is one-to-one relationship. 
experiment at sample point $\mathrm{B}$ and the lowest flows were obtained in June 2019 at sample points A and C (Table 4).

Flow estimates were used to estimate total mass and estimate mass recovery. Results show variable mass recovery, ranging from 1 to $135 \%$ with an average recovery of $53 \%$. Lowest recoveries are mostly associated with Point $\mathrm{C}$ and is attributed to lack of measurements toward the end of the TCDs. For comparison purposes, percent recoveries are compared for total mass passing through for points A and B (Table 5). Lowest mass recoveries for these points are associated with experiments conducted in July and October of 2018. These experiments have the highest total antecedent rainfall.

\section{Discussion and Conclusion}

Transport experiments using rhodamine wt and uranine tracers in a cave located within an eogenetic karst system in northern Puerto Rico show that hydrologic regimes and conditions influence the transport of solutes in these systems. Result indicate that transport velocities and the variance of the temporal concentration distribution at various locations are influenced by total rainfall during the month when the experiments were conducted, as well as the total antecedent rainfall (TAR) during the 3

\begin{tabular}{|l|l|l|l|}
\hline Date & $Q_{A}\left(\mathrm{~m}^{3} / \mathrm{s}\right)$ & $Q_{B}\left(\mathrm{~m}^{3} / \mathrm{s}\right)$ & $Q_{C}\left(\mathrm{~m}^{3} / \mathrm{s}\right)$ \\
\hline July 2018 & 0.001 & 0.005 & 0.002 \\
\hline October 2018 & 0.001 & 0.001 & 0.001 \\
\hline February 2019 & & 0.002 & \\
\hline March 2019 & & 0.002 & \\
\hline June 2019 & 0.0007 & 0.001 & 0.0002 \\
\hline
\end{tabular}

Table 4. Flow estimated from rhodamine wt tracer experiments at points $A, B$, and $C$.

\begin{tabular}{|l|c|}
\hline Date & \% Recovery \\
\hline July 2018 & 77 \\
\hline October 2018 & 13 \\
\hline February 2019 & 81 \\
\hline March 2019 & 135 \\
\hline June 2019 & 116 \\
\hline
\end{tabular}

Table 5. Recovery percentage from rhodamine wt tracer experiments from point $A$ through $B$. months previous to the month-of-testing. The influence of total monthly rainfall during the month of the tracer experiments are attributed to rapid recharge into the conduit cave, whereas the influence of the TAR is attributed to flow previously stored in the groundwater system during previous rainfall events. The influence of the TAR suggests a large groundwater storage component in these aquifers. High TAR results in rapid transport of solutes, even when experiments are conducted during a dry month. High transport velocities are generally related with high relative concentration. High TAR is also associated with long tailing and high variance related to variable velocity fields, mechanical dispersion, and dilution.

\section{Acknowledgement}

Support of the work described is provided through Award Number P42ES017198 from the National Institute of Environmental Health Sciences of the National Institute of Health to the Puerto Rico Testsite for Exploring Contamination Threats (PROTECT) Superfund Research Program Center [Grant number P42ES017198]. Support has also been provided by the NSF to Dr. Ingrid Padilla while serving at the National Science Foundation. The content is solely the responsibility of the authors and does not necessarily represent the official views or policies of the National Science Foundation, National Institute of Environmental Health Sciences and the National Institute of Health. Also, we like to acknowledge the support from Abel Vale, Jonathan Toro, Anaira Román, Jonathan D. Ambrose and Luisa Feliciano.

\section{Reference}

Axelsson, G., Björnsson, G., \& Montalvo, F. 2005. Quantitative Interpretation of Tracer Test Data. World Geothermal Congress, (April), 24-29.

Chapra, S. C. 2003. Surface Water-Quality Modeling. Medtech A Division of Scientific International.

Cherry, G. S., 2001, Simulation of flow in the upper north coast limestone aquifer, Manatí-Vega Baja area , Puerto Rico: U.S. Geological Survey WaterResources Investigations Report 00-4266, 82 p.

Ford, D., and Williams, P. 2007. Karst Hydrogeology and Geomorphology. John Wiley \& Sons, Chichester, England. 
Goldscheider, N., Meiman, J., Pronk, M., \& Smart, C. 2008. Tracer tests in karst hydrogeology and speleology. International Journal of Speleology, 37(1), 27-40. https://doi.org/10.5038/1827806X.37.1.3

Göppert, N., \& Goldscheider, N. 2008. Solute and colloid transport in karst conduits under low- and high-flow conditions. Ground Water, 46(1), 61-68. https://doi.org/10.1111/j.1745-6584.2007.00373.x

Hartmann, A., Goldscheider, N., Wagener, T., Lange, J., \& Weiler, M. 2014. Karst water resources in a changing world: Approaches, of hydrological modeling. Review of Geophysics, (1), 1-25. https://doi.org/10.1002/2013RG000443.Received

Kresic, N. 2013. Water in Karst. McGraw-Hill .

Lauber, U., Ufrecht, W., \& Goldscheider, N. 2014. Spatially resolved information on karst conduit flow from in-cave dye tracing. Hydrology and Earth System Sciences, 18(2), 435-445. https:// doi.org/10.5194/hess-18-435-2014

Longenecker, J., Bechtel, T., Chen, Z., Goldscheider, N., Liesch, T., and Walter, R. (2017) Correlating Global Precipitation Measurement satellite data with karst spring hydrographs for rapid catchment delineation. Geophysical Research Letters, 44(10), 4926-4932.

Lugo AE, Castro LM, Vale A, López T, Prieto EH, Martinó AG, Rolón ARP, Tossas AG, McFarlane DA, Miller T, Rodriguez A, Lundberg J, Thomlinson J, Colón J, Schellekens, JH, Ramos O, Helmer E (2001) Puerto Rican Karst- A Vital Resource. US Department of Agriculture Forest Service General Technical Report WO 65.

Molina-Rivera, W. L. 2009. Source, Use, and Disposition of Freshwater in Puerto Rico, 2005. USGS Science for Changing World, (September), 5. https://doi.org/Fact Sheet 2009-3080

Morales, T., Uriarte, J. A., Antigüedad, I., and Angulo, B. 2010. Solute Transport Modelling in Karst Conduits with Slow Zones During Different Hydrologic Conditions. Journal of Hydrology , 390, 182-189.

National Oceanic and Atmospheric Administration (NOAA). 2019. Available from: https://gis.ncdc. noaa.gov/maps/ncei/cdo/daily
Padilla, I., Irizarry, C., \& Steele, K. 2011. Historical Contamination of Groundwater Resources in the North Coast Karst Aquifers of Puerto Rico. United States Geological Survey. Revista Dimension, 3, 7-12. Retrieved from http://www.pubmedcentral. nih.gov/articlerender.fcgi? $\operatorname{artid}=3999440 \&$ tool $=p$ mcentrez\&rendertype $=$ abstract

Padilla, I. Y., \& Vesper, D. J. 2018. Karst Groundwater Contamination and Public Health. In Karst Groundwater Contamination and Public Health. United States Geological Survey. (pp. 33-49). https://doi.org/10.1007/978-3-319-51070-5

Quinones-Aponte, V. 1986. Water Resources of the Lower Rio Grande of Arecibo Alluvial Valley, Puerto Rico. U.S. Geological Survey. Report 854160.

Renken, R. A. ., Ward, W. C. ., Gill, I. P. ., GómezGómez, F. ., \& Rodríguez-Martínez, J. 2002. Geology and hydrogeology of the Caribbean Islands aquifer system of the commonwealth of Puerto Rico and the U.S. Virgin Islands. US Geological Survey Professional Paper. 1419. Retrieved from http://www.scopus.com/inward/ record.url?eid=2-s2.0-1542636262\&partnerID $=40$ $\& \mathrm{md} 5=\mathrm{a} 8900559 \mathrm{c} 6 \mathrm{~b} 5 \mathrm{c} 4 \mathrm{~b} 9 \mathrm{~d} 6261 \mathrm{a} 5 \mathrm{cb} 230 \mathrm{c} 618$

Torres, N. I., Yu, X., Padilla, I. Y., Macchiavelli, R. E., Ghasemizadeh, R., Kaeli, D.,... Alshawabkeh, A. N. 2018. The influence of hydrogeological and anthropogenic variables on phthalate contamination in eogenetic karst groundwater systems. Environmental Pollution, 237, 298-307. https://doi.org/10.1016/j.envpol.2018.01.106

Veve, T.D., and Taggart, B. E. Atlas of Ground-Water Resources in Puerto Rico and the US Virgin Islands: US Geological Survey Water Resources Investigations Report 94-4198. 1996:151

Yu, X., Ghasemizadeh, R., Padilla, I., Irizarry, C., Kaeli, D., \& Alshawabkeh, A. 2015. Spatiotemporal changes of CVOC concentrations in karst aquifers: analysis of three decades of data from Puerto Rico. The Science of the Total Environment, 511, 1-10. https://doi.org/10.1016/j. scitotenv.2014.12.031 